\title{
The effect of lesser yam based cookies on fasting glucagon-like peptide 1, appetite, and dietary intake in overweight/obese with ad libitum diet
}

Harry Freitag Luglio Muhammad ${ }^{1}$, Annisa Lailatul Fitria ${ }^{1}$, Dewi Ayu Kusumawardhani ${ }^{1}$, Rinta Amalia ${ }^{1}$, Desy Dwi Hapsari', Rina Susilowati², Sunarti Sunarti ${ }^{3}$

${ }^{1}$ Department of Nutrition and Health, Faculty of Medicine, Public Health, and Nursing, Universitas Gadjah Mada

${ }^{2}$ Department of Histology and Cell Biology, Faculty of Medicine, Public Health, and Nursing, Universitas Gadjah Mada

${ }^{3}$ Department of Biochemistry, Faculty of Medicine, Public Health, and Nursing, Universitas Gadjah Mada

\begin{abstract}
Background: Appetite and dietary intake have been associated with obesity and successfulness of weight loss in obese individuals. Glucagon-like peptide 1 is a gut-derived neuropeptide that is produced as a response to dietary intake and associated with appetite. It has been investigated that prebiotic is able to induce GLP-1 production in animal model and humans. Objectives: The aim of this study was to investigate the effect of lesser yam based cookies on fasting GLP-1 plasma, appetite, and dietary intake. Methods: An experimental study was conducted on 15 overweight/obese individuals using cookies made with lesser yam flour for 6 weeks. Fasting GLP-1 level, dietary intake and appetite were measured before and after the intervention. Dietary intake was recorded using a semi-quantitative food frequency questionnaire and appetite was measured using a visual analog scale. Results: After the intervention, the dietary intake includes total energy $(p=0,013)$, protein $(p=0,004)$ and carbohydrate $(p=0,02)$ were significantly reduced. Based on paired t-test that was done in each time point, after the intervention subjects had lower hunger feeling and higher satiety especially at $4(p=0,039)$ and $3(p=0,039)$ hours after breakfast, respectively. Fasting GLP-1 plasma level was not changed after the intervention ( $p>0,05)$. There is no correlation between GLP-1 and dietary intake as well as appetite. Conclusions: We concluded that lesser yam based cookies were able to reduce dietary intake and hunger as well as increase fullness. The fasting GLP-1 concentration did not change after the intervention this was not associated with changes in satiety, fullness, desire to eat or energy intake.
\end{abstract}

KEYWORDS: appetite; GLP-1; intake; overweight; prebiotics

\section{INTRODUCTION}

Obesity is a result of chronic positive energy balance and this is associated with the increased risk of cardiovascular diseases and type 2 diabetes (1). Dietary change such as calorie restriction is a commonly used method for weight loss but this often failed to prevent weight regain after weight loss (2-4). Changes in energy expenditure and appetite after weight loss have been suggested as the important factors in mediating weight regain (5-8).

It has been suggested that gut-derived hormones play an important role in regulating appetite and energy intake. Glucagon-like peptide 1 (GLP-1) is one of the gut-derived peptides that have an important role in regulating food intake and appetite (9). This theory has been supported by studies using the infusion of the pharmacological dose of GLP-1. It was reported that GLP-1 administration was not only able to reduce dietary intake and hunger but also able to increase satiety and fullness (10-12).

GLP-1 production is regulated by diet. Oligofructose saccharide supplementation was associated with a reduction of dietary intake as well as increasing GLP-1 serum concentration in an animal model (13). This effect then further showed in humans (14). It was shown that prebiotic has been associated with improvement of

Corresponding author: Harry Freitag Luglio Muhammad, Department of Nutrition and Health, Faculty of Medicine, Public Health, and Nursing, Universitas Gadjah Mada, Indonesia, Jalan Farmako, Sekip Utara, Yogyakarta, Indonesia, Phone +62 274 547775, e-mail: harryfreitag@ugm.ac.id 
appetite via GLP-1, however, the majority of those the intervention studies used supplementation. Therefore, this study was aimed to evaluate the effect of cookies made with lesser yam (Dioscorea esculenta), a natural source of inulin, on appetite, energy intake, and GLP1 concentration among adults with obesity. This is an additional analysis of a study that has been published before (15).

\section{METHODS}

This is an experimental study with pre-post test design. A total of 15 overweight/obese adults participated in this study. Subjects were selected using purposive sampling. Announcement for study recruitment was done using fliers and social media. The subjects who were diagnosed with chronic diseases, pregnant, breastfeeding, smoking and receiving any kind of weight loss intervention were not included in this study. This study has been approved by the Medical and Health Research Ethics Committee, Faculty of Medicine, Universitas Gadjah Mada, Indonesia. This study followed the ethical guidelines of the 1975 Declaration of Helsinki.

The lesser yam was given as cookies for snacks. Subjects were asked to finish their daily intake 87 grams of cookies a day, which contains 37 grams lesser yam flour (equal with 5.4 grams inulin). An optimization of the cookies was done before the study was started by mixing the lesser yam flour with wheat flour $(80 \%$ of lesser yam and $20 \%$ of the wheat flour). The purpose of this combination was to improve the acceptability of the cookies. The total calorie contribution of lesser yam cookies on total energy intake is around $300 \mathrm{kcal}$ depending on variations of cookies. Subjects were free to consume the cookies throughout the day. This intervention was done in 6 consecutive weeks.

The measurements were done two times, before and after the intervention. Before measurement day, subjects were asked to do 8 hours overnight fasting (started at $10.00 \mathrm{pm}$ ). The anthropometric measurements and blood sampling were done in the morning. Body weight was measured using a digital scale $(0.01 \mathrm{~kg}$ precision, Omron Karada Scan HBF-375, Japan) and height was measured using microtoise $(0.1 \mathrm{~cm}$ precision,
GEA medical, Indonesia). Body mass index (BMI) was calculated by dividing body weight $(\mathrm{kg})$ with squared height $\left(\mathrm{m}^{2}\right)$. A total of $5 \mathrm{ml}$ of blood was collected using ethylene diamine tetra acetic acid (EDTA) tube. Following collection, the blood was centrifuged, the plasma was taken and stored at $-80^{\circ} \mathrm{C}$ freezer. Fasting GLP-1 was measured using enzyme immunoassay (Sigma Aldrich).

Data on dietary intake and appetite was measured by an interview with trained enumerators. Dietary intake was measured using a semi-quantitative food frequency questionnaire before and after the intervention. The intake of foods and beverages including the lesser yam cookies were recorded. The dietary components were analyzed using Nutrisurvey software (EBISpro, Germany, http://www.nutrisurvey.de) with a database for Indonesian foods. Appetite rating was measured using a visual analog scale with these 4 questions: 1)"How hungry do you feel?"; 2)“How satisfied do you feel?"; 3)“How full do you feel?"; 4)“How much do you feel you can eat?". Subjects were asked to fill the line between 0 and $100(10 \mathrm{~cm}$ length) to express quantify the degree of appetite. This measurement was done 7 times includes fasting ( 0 hours) and every 1 hour after breakfast 6 times. The initial appetite rating question at 0 hours was done before the blood sampling. Following the blood sampling, subjects were given breakfast with the same portion and dietary components. Subjects were not allowed to eat and drink (in exception to water) during this measurement. Appetite was analyzed in 2 ways: 1) time point changes in each appetite ratings, and 2) calculation of the area under the curve (AUC) for each component of appetite rating.

All datasets were subject to Saphiro-Wilk normality test, the normally distributed data and not normally distributed data were analyzed accordingly to the type of dataset. A paired t-test was used to examine the changes in body weight, BMI, energy intake, appetite ratings, and GLP-1 concentration. A Pearson correlation test was used to examine the correlation between GLP-1 concentration post-intervention and changes in appetite ratings (hunger, satiety, fullness, desire to eat). The significance was based on a $\mathrm{p}$-value of less than 0,05 . A linear regression test was used to analyze the correlation between changes in appetite rating and changes in total energy intake with 
correction for potential confounding factors such as age, sex, and initial BMI. Statistical analysis was done using JASP (The University of Amsterdam). Ethical clearance was obtained from the Medical and Health Research Ethics Committee (MHREC) Faculty of Medicine, Universitas Gadjah Mada, Indonesia. All subjects read and signed informed consent prior to data collection.

\section{RESULTS}

Initially, a total of 37 subjects participated in this study but only 15 agreed to participate in the appetite analysis. From a total of 87 grams of cookies a day, the subjects only consume an average of 36,2 grams of cookies a day. The reason why subjects did not finish the cookies because of the bitter after taste and few of them experience gastrointestinal discomfort. There were no significant changes in body weight and BMI after the intervention. The total energy intake was significantly reduced but there were no differences in the macronutrient composition of the diet (Table 1).

In this study, the area under the curve (AUC) of each appetite ratings (hunger, satiety, fullness, and desire to eat) was not significantly changed after the intervention. In order to evaluate the changes in appetite rating, an individual analysis was done using a paired t-test. In this analysis, all parameters were compared at every one hour starting at 0 hours (fasting) until 6 hours after having breakfast. As shown in Figure 1, there were slight changes in the feeling of hunger and satiety.

Table 1. Changes in appetite ratings and dietary intake after intervention with lesser yam based cookies

\begin{tabular}{lccc}
\hline & Pre & Post & p \\
\hline Body weight $(\mathrm{kg})$ & $81.4 \pm 3.9$ & $81.3 \pm 3.9$ & 0.816 \\
Body mass index $\left(\mathrm{kg} / \mathrm{m}^{2}\right)$ & $30.8 \pm 1.3$ & $30.8 \pm 1.2$ & 0.678 \\
Glucagon like peptide 1 $(\mathrm{ug} / \mathrm{dL})$ & $61.8 \pm 2.4$ & $59.0 \pm 1.4$ & 0.249 \\
Dietary intake & & & \\
$\quad$ Energy (kcal) & $2224.2 \pm 187.8$ & $1812.2 \pm 122.7$ & 0.013 \\
\% protein & $14.3 \pm 0.9$ & $13.2 \pm 0.8$ & 0.189 \\
\% fat & $29.2 \pm 1.9$ & $32.3 \pm 1.4$ & 0.164 \\
\% carbohydrate & $52.5 \pm 1.5$ & $52.1 \pm 2.1$ & 0.845 \\
Appetite rating & & & \\
Satiety (AUC score) & $365.7 \pm 34.0$ & $373.5 \pm 33.0$ & 0.752 \\
Fullness (AUC score) & $335.3 \pm 20.5$ & $374.3 \pm 26.7$ & 0.163 \\
Desire to eat (AUC score) & $325.7 \pm 32.9$ & $314.1 \pm 37.7$ & 0.717 \\
Hunger (AUC score) & $264.5 \pm 33.7$ & $239.3 \pm 35.1$ & 0.444 \\
\hline
\end{tabular}

*Paired t-test of comparison of measurements before and after the intervention. AUC: area under the curve

Table 2. The correlation between changes in energy intake, plasma GLP-1 and changes in appetite rating

\begin{tabular}{lcccc}
\hline & Pearson's r & $\mathbf{p}$ & $\boldsymbol{\beta}^{*}$ & $\mathbf{p}^{*}$ \\
\hline Changes in energy intake & & & & \\
$\quad$ Changes in hunger & 0.178 & 0.526 & 0.175 & 0.612 \\
Changes in satiety & -0.697 & 0.004 & -0.775 & 0.007 \\
Changes in fullness & -0.498 & 0.059 & -0.682 & 0.065 \\
$\quad$ Changes in desire to eat & 0.558 & 0.031 & 0.589 & 0.056 \\
Plasma GLP-1 post intervention & & & & \\
Changes in hunger & -0.132 & 0.640 & -0.600 & 0.162 \\
Changes in satiety & -0.136 & 0.630 & -0.335 & 0.452 \\
Changes in fullness & 0.233 & 0.403 & 0.240 & 0.532 \\
Changes in desire to eat & 0.131 & 0.643 & 0.055 & 0.906 \\
\hline
\end{tabular}

*Linear regression test with correction for age, sex, and body mass index. GLP-1: glucagon like peptide-1. 
A. How hungry do you feel?

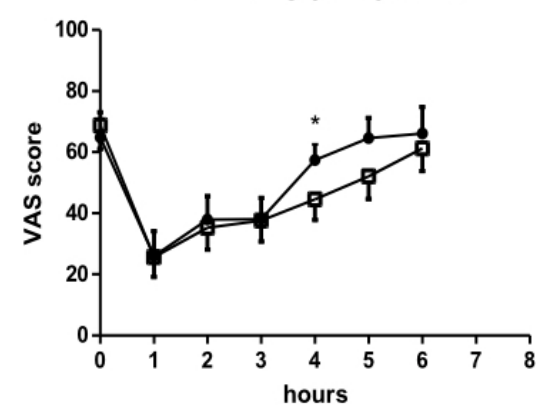

C. How full do you feel?

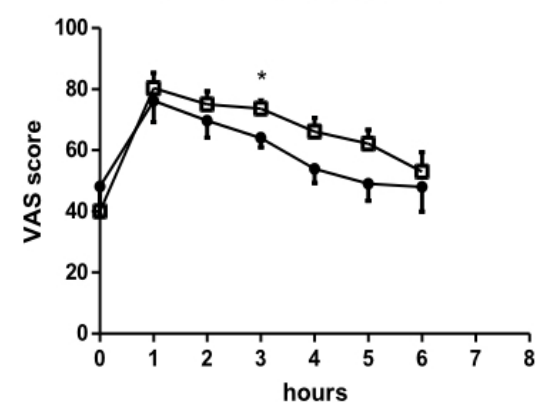

B. How satisfied do you feel?

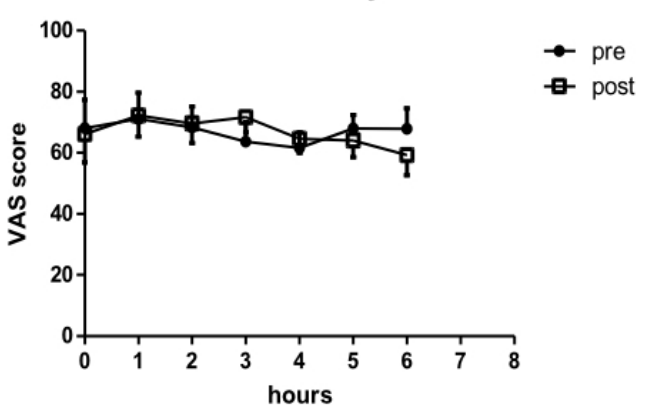

D. How much do you feel you can eat?

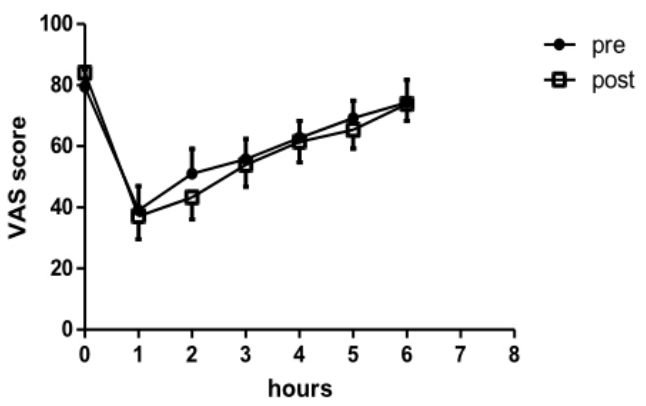

Figure 1. Appetite rating pre- and post- intervention with lesser yam based cookies

Based on paired t-test that was done in each time point, the after the intervention subjects had lower hunger and higher fullness at $4(p=0,039)$ and $3(p=0,039)$ hours after breakfast, respectively.

In order to check whether the changes in appetite rating was associated with changes in total energy intake, a correlation analysis was done. In this analysis, we showed that changes in satiety $(\mathrm{p}=0.004)$ and desire to eat $(p=0.031)$ were significantly correlated with changes in total energy intake (Table 2). Additionally, after correction for age, sex, and BMI, we found that only changes in satiety were negatively correlated with changes in energy intake $(p=0.007)$. There was no significant difference in GLP-1 after the intervention. In addition, we also found that fasting GLP-1 concentration at the end of the intervention was not correlated with any changes in any appetite ratings (Table 2).

\section{DISCUSSION}

Lesser yam contains $14,6 \%$ of inulin (dry basis) therefore this food item was chosen as the dietary source of inulin in this study (16). This food item has been known by indigenous people who live in several areas in Java Island (Indonesia) as one of their staple food. However, because the modernization is widespread throughout the country, people are more likely to consume rice or flour-based foods rather than traditional lesser yam meal. In this study, the lesser yam was prepared as cookies instead of the traditional dishes because it is more easy, efficient and convenient for a longer period of study. The intervention with inulin rich-lesser yam based cookies was able to reduce hunger and increase satiety. We found that total energy intake was significantly reduced after the intervention. This finding was supported by Cani et al. (14) who showed that two weeks of 16 grams a day inulin 
supplementation was associated with the reduction of hunger. They also see the slight reduction in dietary intake at the subject group receiving inulin supplementation compared to control (16).

Liber and Szajewska conducted a systematic review of trials studying the role of inulin-type fructan on appetite and dietary intake (17). The effect of inulin on appetite was not conclusive. From 4 randomized control trials (RCTs) that were compiled by Liber and Szajewska, they only found 1 RCT that showed the significant changes in appetite after inulin supplementation $(14,18-20)$. The study done in overweight/obese adults was failed to prove the long-term effect of inulin supplementation on the regulation of appetite (18). In the review, Liber and Szajewska also showed that the inulin supplementation did not significantly alter energy intake from the majority of RCTs (14,18,19-23). Only Cani et al. (14) showed the effect of inulin supplementation on reducing energy intake in subjects. The role of inulin and other prebiotics on appetite control and dietary intake have been investigated before. It seems that GLP-1, the gut-derived neuropeptides, was responsible for the communication between gut and brain by regulating appetite. Cani et al. (14) reported that the administration of 100 grams of inulin-type fructan to male Wistar rats for 3 weeks was associated with a reduction of energy intake. The mRNA expression of GLP-1 in the proximal colonic mucosa of the rat was also higher in the treatment group showing that the fructan was responsible for GLP-1 production by intestinal cells. GLP-1 regulates appetite and feeding behavior via its interaction with the central nervous system (9).

In the current study, we reported that consumption of the lesser yam based cookies for 6 weeks do not affect fasting plasma GLP-1 concentration. It might since we only used fasting GLP-1 and this might not be able to illustrate the GLP-1 response throughout the diet. We also suspect that the lack of changes in fasting GLP-1 was due to inadequate lesser yam intake during the intervention.

The unique point of this study is inulin was delivered as the real food instead of a supplement. However, the usage of food as the source of inulin was also the drawback because it is difficult to obtain good compliance throughout 6 weeks of intervention. As a result, we found that subjects only consumed less than the intended dose. This will, of course, affect the biological effect of the intervention. Therefore, more optimation for the recipe of lesser yam cookies is needed to improve acceptance for product. In addition, we also did not include a placebo in this study, which might affect the interpretation of the data in this study.

\section{CONCLUSIONS}

In summary, we found that lesser yam based cookies were associated with the reduction of hunger and increment in fullness amongst individuals with obesity. The changes in appetite fasting lead to changes in total energy intake. The fasting GLP-1 concentration did not change after the intervention this was not associated with appetite ratings or energy intake.

\section{Declaration of conflicting interests}

The authors declare that they have no competing interests.

\section{REFERENCES}

1. GBD 2015 Obesity Collaborators, et al. Health effects of overweight and obesity in 195 countries over 25 years. N Engl J Med. 2017;377(1):13-27. doi: 10.1056/ nejmoa1614362

2. Weiss EC, Galuska DA, Kettel Khan L, Gillespie C, Serdula MK. Weight regain in U.S. adults who experienced substantial weight loss, 1999-2002. Am J Prev Med. 2007;33(1):34-40. doi: 10.1016/j.amepre.2007.02.040

3. Turk MW, Yang K, Hravnak M, Sereika SM, Ewing LJ, Burke LE. Randomized clinical trials of weight-loss maintenance: a review. J Cardiovasc Nurs. 2009;24(1):5880. doi: 10.1097/01.JCN.0000317471.58048.32

4. Kraschnewski JL, Boan J, Esposito J, Sherwood NE, Lehman EB, Kephart DK, et al. Long-term weight loss maintenance in the United States. Int J Obes (Lond). 2010;34(11):1644-54. doi: 10.1038/ijo.2010.94

5. Weigle DS, Sande KJ, Iverius PH, Monsen ER, Brunzell JD. Weight loss leads to a marked decrease in nonresting energy expenditure in ambulatory human subjects. Metabolism. 1988;37(10):930-6. doi: 10.1016/00260495(88)90149-7

6. Doucet E, Imbeault P, St-Pierre S, Alméras N, Mauriège $\mathrm{P}$, Després JP, et al. Greater than predicted decrease in 
energy expenditure during exercise after body weight loss in obese men. Clin Sci (Lond). 2003;105(1):89-95. doi: $10.1042 /$ CS20020252

7. Mariman ECM. Human biology of weight maintenance after weight loss. J Nutrigenet Nutrigenomics. 2012;5(1):13-25. doi: 10.1159/000337081

8. Sumithran P, Prendergast LA, Delbridge E, Purcell K, Shulkes A, Kriketos A, et al. Long-term persistence of hormonal adaptations to weight loss. N Eng J Med. 2011;365(17):1597-604. doi: 10.1056/NEJMoa1 105816

9. Van Bloemendaal L, ten Kulve JS, La Fleur SE, Ijzerman RG, Diamant M. Effects of glucagon-like peptide 1 on appetite and body weight: Focus on the CNS. J Endocrinol. 2014;221(1). doi: 10.1530/JOE-13-0414

10. Näslund E, Gutniak M, Skogar S, Rössner S, Hellström PM. Glucagon-like peptide 1 increases the period of postprandial satiety and slows gastric emptying in obese men. Am J Clin Nutr. 1998;68(3):525-30. doi: 10.1093/ ajen/68.3.525

11. Flint A, Raben A, Astrup A, Holst JJ. Glucagon-like peptide 1 promotes satiety and suppresses energy intake in humans. J Clin Invest. 1998;101(3):515-20. doi: 10.1172/ JCI990

12. Gutzwiller JP, Drewe J, Göke B, Schmidt H, Rohrer B, Lareida J, et al. Glucagon-like peptide-1 promotes satiety and reduces food intake in patients with diabetes mellitus type 2. Am J Physiol. 1999;276(5):R1541-4. doi: 10.1152/ ajpregu.1999.276.5.R1541

13. Cani PD, Dewever C, Delzenne NM. Inulin-type fructans modulate gastrointestinal peptides involved in appetite regulation (glucagon-like peptide-1 and ghrelin) in rats. Br J Nutr. 2004;92(3):521-6. doi: 10.1079/bjn20041225

14. Cani PD, Lecourt E, Dewulf EM, Sohet FM, Pachikian BD, Naslain D, et al. Gut microbiota fermentation of prebiotics increases satietogenic and incretin gut peptide production with consequences for appetite sensation and glucose response after a meal. Am J Clin Nutr. 2009; 90(5):1236-43. doi: 10.3945/ajen.2009.28095

15. Luglio HF, Fitria AL, Kusumawardhani DA, Amalia R, Hapsari DD, Susilowati R, et al. Lesser yam (Dioscorea esculenta) based cookies improves lipid profile in overweight/obese adults with an ad libitum diet via glucagon like peptide 1. Nutrition and Food Science. 2016;46(3):336-43. doi: 10.1108/NFS-10-2015-0131

16. Wilujeng KG. Pembuatan inulin bubuk dari umbi gembili (Dioscorea esculenta) dengan metode foam mat drying [Thesis]. Surabaya: Universitas Pembangunan Nasional Veteran; 2010.

17. Liber A, Szajewska H. Effects of inulin-type fructans on appetite, energy intake, and body weight in children and adults: systematic review of randomized controlled trials. Ann Nutr Metab. 2013;63(1-2):42-54. doi: 10.1159/000350312

18. Parnell JA, Reimer RA. Weight loss during oligofructose supplementation is associated with decreased ghrelin and increased peptide YY in overweight and obese adults. Am J Clin Nutr. 2009;89(6):1751-9. doi: 10.3945/ ajcn.2009.27465

19. Harrold JA, Hughes GM, O'Shiel K, Quinn E, Boyland EJ, Williams NJ, et al. Acute effects of a herb extract formulation and inulin fibre on appetite, energy intake and food choice. Appetite. 2013;62:84-90. doi: 10.1016/j. appet.2012.11.018

20. Verhoef SPM, Meyer D, Westerterp KR. Effects of oligofructose on appetite profile, glucagon-like peptide 1 and peptide YY3-36 concentrations and energy intake. Br J Nutr. 2011;106(11):1757-62. doi: 10.1017/ S0007114511002194

21. Giacco R, Clemente G, Luongo D, Lasorella G, Fiume I, Brouns F, et al. Effects of short-chain fructooligosaccharides on glucose and lipid metabolism in mild hypercholesterolaemic individuals. Clin Nutr. 2004;23(3):331-40. doi: 10.1016/j.clnu.2003.07.010

22. Hess JR, Birkett AM, Thomas W, Slavin JL. Effects of short-chain fructooligosaccharides on satiety responses in healthy men and women. Appetite. 2011;56(1):128-34. doi: 10.1016/j.appet.2010.12.005

23. Karalus M, Clark M, Greaves KA, Thomas W, Vickers Z, Kuyama M, et al. Fermentable fibers do not affect satiety or food intake by women who do not practice restrained eating. J Acad Nutr Diet. 2012;112(9):1356-62. doi: 10.1016/j.jand.2012.05.022 